\section{Philadelphia Chromosome Positive B-lymphoblastic Leukemia in an Infant}

Sir,

Acute Lymphoblastic Leukemia (ALL) in infancy is a rare entity with reported incidence of $2.5-5 \%$ of total childhood ALL. ${ }^{1}$ It usually presents with organomegaly, hyperleukocytosis, central nervous system (CNS) involvement and B-cell phenotype. Acquired mixed lineage leukemia (MLL) gene rearrangement on chromosome 11 q23 is the most observed cytogenetic abnormality in infantile ALL with an incidence of $\sim 80 \% .{ }^{2}$ The Philadelphia (Ph) chromosome positive B-lymphoblastic leukemia (B-ALL) is uncommon in childhood $(<5 \%)$ and exceptionally rare in infants. ${ }^{3}$ Here, we report a case of infantile B-ALL with presence of $\mathrm{Ph}$ chromosome and absence of MLL gene rearrangement.

An 11-month infant boy presented with complains of fever and irritability. On examination, he had cervical lymphadenopathy, and hepato-splenomegaly. Complete blood count (CBC) showed haemoglobin $(\mathrm{Hb}) 8.7 \mathrm{gm} / \mathrm{dl}$, total leucocyte count (TLC) $10.24 \times 10^{9} / \mathrm{L}$, and platelet count $38 \times 10^{9} / \mathrm{L}$ with $22 \%$ blasts. Diagnosis of B-ALL was confirmed by flow cytometry, which revealed $82 \%$ blasts, positive for TdT, CD19, CD79a and CD10 immunostains. Karyotype showed presence of Ph chromosome in 10 out of 20 analysed cells. Fluorescent in situ hybridisation (FISH) results were consistent with presence of BCR/ABL1 fusion signals in $36.7 \%$ of nuclei. However, MLL gene rearrangement and ETV6/RUNX1 were not found. Polymerase chain reaction (RT-PCR) showed BCR-ABL1 p210 mRNA transcript in 32\% of total ABL1. The diagnostic cerebrospinal fluid (CSF) showed white cell count of $33 / \mathrm{ul}$ with $65 \%$ blast cells. Hence, the final diagnosis of B-ALL with Ph chromosome and central nervous system (CNS) involvement was established.

The case was discussed in Tumour Board. Based on poor anticipated response to chemotherapy, allogenic hematopoietic stem cell transplant in first remission (CR1) was proposed. The family was counselled for the limitation of transplant facility in our settings; and referral to transplant centre was advised for the curative treatment. However, the family continued to follow with us, where palliative care was offered; but the child died due to sepsis within 4 weeks of diagnosis.

ALL in infants is an aggressive disease with higher chances of treatment failure; and it exhibit MLL gene rearrangement as a hallmark cytogenetic abnormality. ${ }^{4} \mathrm{Ph}$ chromosome is a disease defining feature of chronic myeloid leukemia (CML), and it is uncommon (3-5\%) in childhood ALL and exceptionally rare in infants with ALL. Moreover, more than $90 \%$ of childhood Ph+ ALL patients have a $190-k D a$ BCR-ABL fusion protein; whereas, we found p210 fusion protein in our case, that is commonly described in CML. ${ }^{5}$ This unique cytogenetic finding and lack of MLL gene rearrangement in our case, warrants its reporting for awareness and therapeutic relevance.

\section{CONFLICT OF INTEREST:}

The authors declared no conflict of interest.

\section{AUTHORS' CONTRIBUTION:}

HK: Design of work, manuscript writing. NM: Data collection, manuscriptwriting. $\mathrm{NJ}$ : Concept, proofreading, submission.

\section{REFERENCES}

1. Cherungonath A, Appaji L, Padma M, Arunakumari BS, Arunkumar AR, Avinash $\mathrm{T}$, et al. Profile of acute lymphoblastic leukemia in children under 2 years of age. Indian J Med Paediatr Oncol 2018; 39(3):307-11. DOI: 10.4103/ijmpo.ijmpo_10_17.

2. Biondi A, Cimino G, Pieters R. Biological and therapeutic aspects of infant leukemia. Blood 2000; 96(1):24-33.

3. Sugapriya D, Preethi S, Shanthi P, Chandra N, Jeyaraman G, Sachdanandam $P$, et al. BCR-ABL translocation in pediatric acute lymphoblastic leukemia in Southern India. Indian J Hematol Blood Transfus 2012; 28(1):37-41. doi: 10.1007/ s12288-011-0096-9.

4. Tomizawa D. Recent progress in the treatment of infant acute lymphoblastic leukemia. Pediatrics Int 2015; 57(5):811-9. doi: 10.1111/ped.12758.

5. Slayton WB, Schultz KR, Silverman LB, Hunger SP. How we approach Philadelphia chromosome-positive acute lymphoblastic leukemia in children and young adults. Pediatr Blood Cancer 2020; 67(10):e28543. doi: $10.1002 / p b c .28543$.

Hadia Khanani ${ }^{1}$, Neelum Mansoor ${ }^{2}$ and Naeem Jabbar ${ }^{2}$

${ }^{1}$ Department of Pediatric Haemalogy Oncology, The Indus Hospital, Karachi, Pakistan

${ }^{2}$ Department of Haematology, The Indus Hospital, Karachi, Pakistan

Correspondence to: Dr. Naeem Jabbar, Department of Haematology, The Indus Hospital, Karachi, Pakistan E-mail:drnaim2005@hotmail.com

Received: October 16, 2020; Revised: November 19, 2020; Accepted: November 27, 2020

DOI: https://doi.org/10.29271/jcpsp.2021.11.1386 